\title{
Canopy flow and aspects of the response of plants protected by herbaceous shelterbelts and wood fences
}

\author{
U. Boldes ${ }^{\mathrm{a}}$, A. Golberg ${ }^{\mathrm{b}}$, J. Marañón Di Leo ${ }^{\mathrm{a}}$, \\ J. Colman ${ }^{\mathrm{a}}$, A. Scarabino ${ }^{\mathrm{a}, *}$ \\ ${ }^{a}$ Laboratorio de Capa Limite y Fluidodinámica Ambiental, Facultad de Ingeniería Universidad Nacional de \\ La Plata, Calles 48 y 116, La Planta, Argentina \\ ${ }^{\mathrm{b}}$ Facultad de Agronomía, Universidad Nacional de La Pampa, Argentina
}

\begin{abstract}
Field experiments have been conducted in the semiarid southwest region of La Pampa, Argentina, in order to investigate the effect of different types of windbreak on wind characteristics and growth parameters of wheat (Triticum aestivum, Buck Charrua variety) within the sheltered region.

Windbreaks decrease wind speed, reducing damage to the crop and improving yield and quality. Sheltering may improve microclimate conditions for plant growth and protects the soil from wind erosion.

Aspects of the sheltering ability of four different windbreaks have been tested: single and double row herbaceous (Tritio secale) shelterbelts, and two different artificial wooden fences, with the same overall average porosity, but with different porosity distributions. Mean velocity, turbulence intensity, skewness distributions and spectral and wavelet analysis have been performed in order to characterise the turbulent flow downstream of the different windbreaks. Wheat grain yield and harvest index were compared with adjacent unsheltered plantations.

The single and double row shelterbelts enhanced the grain yield and the harvest index of the protected plants. An influence of the turbulent structure on plant growth is suggested by the different response of plants sheltered by the two types of artificial fences.

(C) 2002 Elsevier Science Ltd. All rights reserved.
\end{abstract}

Keywords: Wind sheltering; Wake flow; Turbulence in plant canopies; Coherent structures; Agricultural aerodynamics

\footnotetext{
*Corresponding author.

E-mail address: aescarbi@ing.unlp.edu.ar (A. Scarabino).
} 


\section{Introduction}

The turbulent flow around artificial windbreaks in neutrally stable air has often been measured [1-4]. The early works of Jensen [5] describe the basic aerodynamics of wind shelter and its effects on climate and crops. Windbreaks for crop protection calm the incident wind generating a protected zone of considerable downwind extent. Many definitions have been presented for shelter effects. Among others, Borrelli et al. [6] developed an equation for the protected downwind distance in the lee of a windbreak, and Argent [7] characterised shelter effects by a normalised gust speed.

It is not easy to quantify the economics of shelter. Several different variables must be considered: yield return, land occupation and soil conservation [8]. The economic value of shelter has been analysed by Brandtle et al. [9], who demonstrated that the installation of windbreaks occupying $5 \%$ of the field was a good investment. They found that long-term improvements of only $6 \%$ compensate the costs of the windbreak and the loss of output from surface occupied by the windbreak.

Two fluid dynamic zones with distinct downwind extent have been identified in the lee of windbreaks of height $H$ in near neutral conditions with perpendicular winds: a relatively small quite zone ranging approximately from $5 H$ to $8 H$, and a larger wake zone with a downwind extent of more than $10 H$ in which a certain degree of protection was found. Mulhearn and Bradley [10] and Plate [11] among others have discussed the downstream development of velocity and shear stress distributions in the wake of a porous shelterbelt.

The existence of moderate air flow in the sheltered region makes possible the existence of different flow patterns governing the essential gaseous transport processes, in which heat, water vapour and gases are advected, mixed and exchanged [12]. Air motion is significant for plant growth [13]. As plant response is species dependent and related to multiple factors, it is not easy to describe the particular influence of wind on plant growth. Experimental evidence indicates that the atmospheric flow within and above plant canopies is integrated by a contribution of intermittent vortical structures involving very different scales, which influence the vertical transport of momentum, heat and moisture [14-17]. Wadsworth [18] inferred the possibility of a particular favourable wind speed for plant growth, depending on plant species and soil water potential.

The aeroelastic response of the plant elements to the incident non-stationary fluid dynamic patterns will define the type and magnitude of the mechanical stimuli acting on the canopy elements [19], influencing also the transpiration rate [20] and the plant surface temperatures [21]. Telewski and Jaffe [22], Telewski [12] and Stokes et al. [23] among others reported wind-induced growth and developmental changes. Goodman and Ennos [24,25] studied the effects of mechanical support and regular stem flexure on the growth, morphology and mechanical properties of maize and sunflower plants exposed to the wind. They reported an increase in the structural strength of roots and stem bases, for the plants that were free to sway in the wind. Baker et al. [26] and Berry et al. [27] studied different ways to reduce wind-induced root and stem lodging in wheat. 
Because of the lack of a theory correlating plant growth and the turbulent structure of the incident wind, most of the existing experimental work concerning plant responses to wind has been described in terms of steady mean velocities, without a characterisation of the turbulent eddies of the natural wind. Thus, these results do not reflect the real influence of the involved time-dependent threedimensional fluid dynamic phenomena.

Plants interact with and process the oncoming wind, generating particular fluiddynamic patterns, which influence the momentum transport, the uptake of carbon dioxide and the release of oxygen and water vapour. Plants growing in atmospheric surface layers with prevailing large-scale eddies, generated by the aerodynamic characteristics of upwind obstacles, are exposed to different mechanical stimuli and undergo different advective gaseous transport processes than plants immersed in small-scale turbulence. Oncoming gusts with spatial scales larger than the leaf dimensions bend the elastic canopy elements, storing elastic energy in the branches and leaves. Subsequently, the canopy elements bounce back, shaking the air and generating turbulence while releasing the gust-generated elastic energy. Oncoming vortex structures are "sliced" by leaves and branches and interact with the smallscale turbulence generated by the canopy elements.

In a crop plantation the concentration and distribution of leaves vary with height. This porosity variation assists in the generation of different turbulent structures of different scales and intensity, which drive the advective gaseous transport processes. The influence of porosity distribution of windbreaks on sheltering efficiency is still a matter of controversy. Sheltering efficiency focused on agricultural applications depends on many factors. Under a fluid dynamic perspective, the most important effect of shelter is the reduction of wind velocity in a protected zone as large as possible. An agronomic perception is more complex. Different plant species require different microclimate parameters: temperature, humidity, velocity $[13,18,22]$. Thus, the sheltering efficiency of a windbreak should also be related to the particular species to be protected and the environmental conditions.

Rosenberg et al. [28], and Wilson [29], among others, suggest that increasing porosity along the lower surface of a windbreak would enhance its sheltering ability as a consequence of the diminution of the energy associated to the fence top shear layer and the reduction of the scale and velocity of the shear layer eddies that penetrate into the wake. On the other hand, Grunert et al. [30] prefer porosity reductions in the fence surface along the ground. Additionally, McNaughton [31] claims that the protected zone of porous windbreaks is much smaller than that admitted in the classical windbreak theory.

In this report we describe some characteristics of the turbulent wind immediately behind single- and double-row herbaceous shelterbelts and two artificial fences with the same overall porosity but different porosity distributions. We also describe wheat growth parameters of the plants protected by these windbreaks compared with adjacent unsheltered plantations. 


\section{Methods}

The tests were carried out in the experimental field of the Facultad de Agronomía, Universidad Nacional de La Pampa, Santa Rosa, La Pampa, Argentina, located in the southwest region of the semiarid Pampa $\left(35^{\circ} \mathrm{S}-65^{\circ} \mathrm{W}\right)$. The yearly mean temperature is $16^{\circ} \mathrm{C}$; the mean temperature in January is $24^{\circ} \mathrm{C}$ and in July $8^{\circ} \mathrm{C}$, with a yearly mean rainfall of $650 \mathrm{~mm}$. The yearly mean wind velocity is $15 \mathrm{~km} \mathrm{~h}^{-1}$. Wind prevailing directions are N-NE (40\%) and S-SW (40\%) (Fig. 1). The most intense winds occur in spring (September-December). The dry winter and extremely windy early spring seasons promote crop damage due to wind intensity and wind-blown sand.

\subsection{Plant growth analysis}

Buck charrua variety wheat plants were sown at a rate of 100 seeds $\mathrm{m}^{-1}$ along E-W oriented rows, with a density of $130 \mathrm{~kg} \mathrm{ha}^{-1}$. The distance between consecutive wheat rows was $15 \mathrm{~cm}$. For each subplot, sampling areas of $0.50 \mathrm{~m} \times 0.20 \mathrm{~m}$ were harvested, located $1.16 \mathrm{~m}$ downwind of each shelterbelt. These representative areas were selected for the shelterbelts protecting from northern and from southern winds,

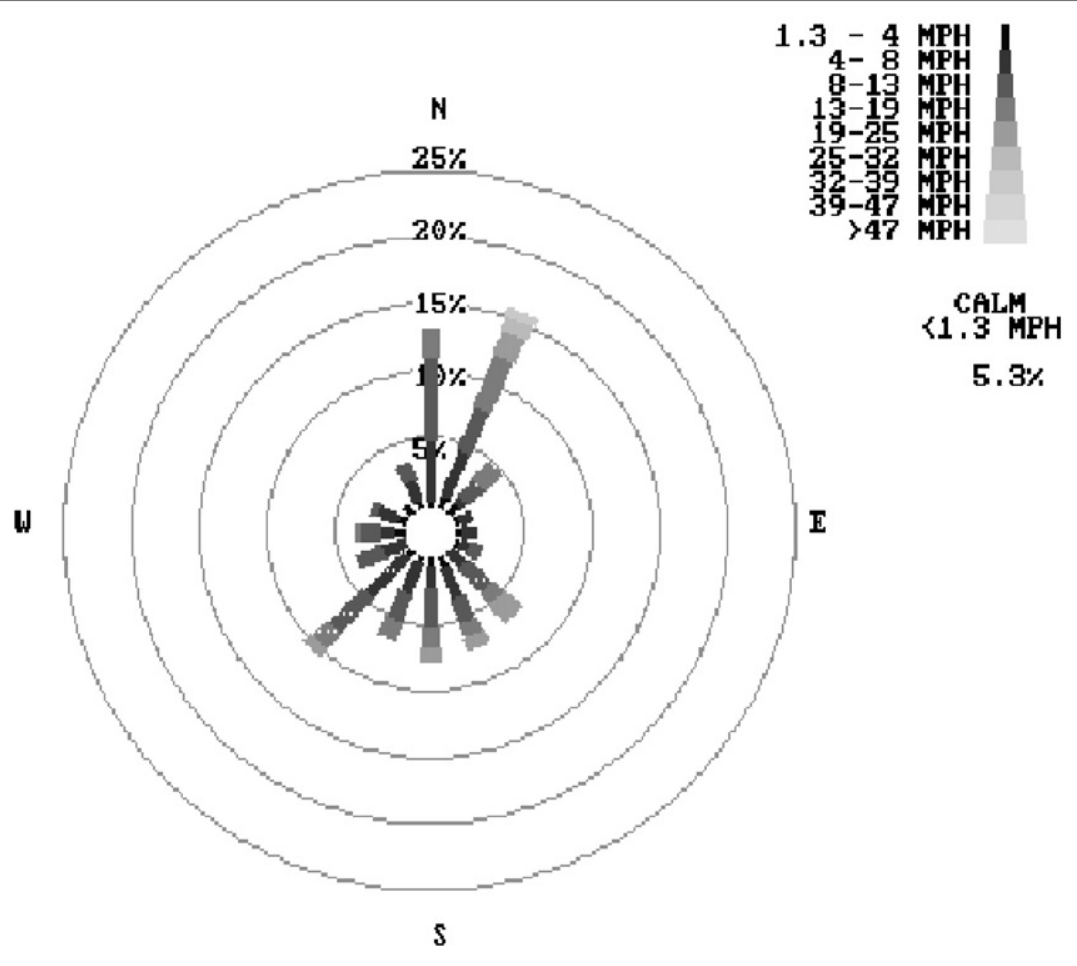

Fig. 1. Wind rose at La Pampa, September 1999. 
respectively. The calculated mean values have been obtained from four repetitions for each wind direction.

For the narrow and wide gap wooden fences, to be described in Section 2.2, one control plot was chosen for each wind direction. At the end of the experiment on December 23, 1999, the wheat harvest was performed in a crop area of $0.250 \mathrm{~m}^{2}$.

The wheat plants were chopped at the base of the stem and heated in a stove to $65^{\circ} \mathrm{C}$ until constant weight was achieved. Then the material of each sample area was weighed in order to obtain the total biomass. The ears were separated from the plants and threshed by hand. To determine the harvest index (HI), defined as the weight of grain divided by the total plant weight, the grains and the straw of each plot were independently weighed. The HI and grain yield of sheltered plots were compared with nearby control subplots (non-sheltered plants), in order to minimise differences in soil (Fig. 2).

\subsection{Herbaceous fences}

Approximately $70 \mathrm{~cm}(H)$ tall single- and double-row $(15 \mathrm{~cm}$ apart) shelterbelts of Triticale have been tested. These herbaceous shelterbelts were grown within wheat

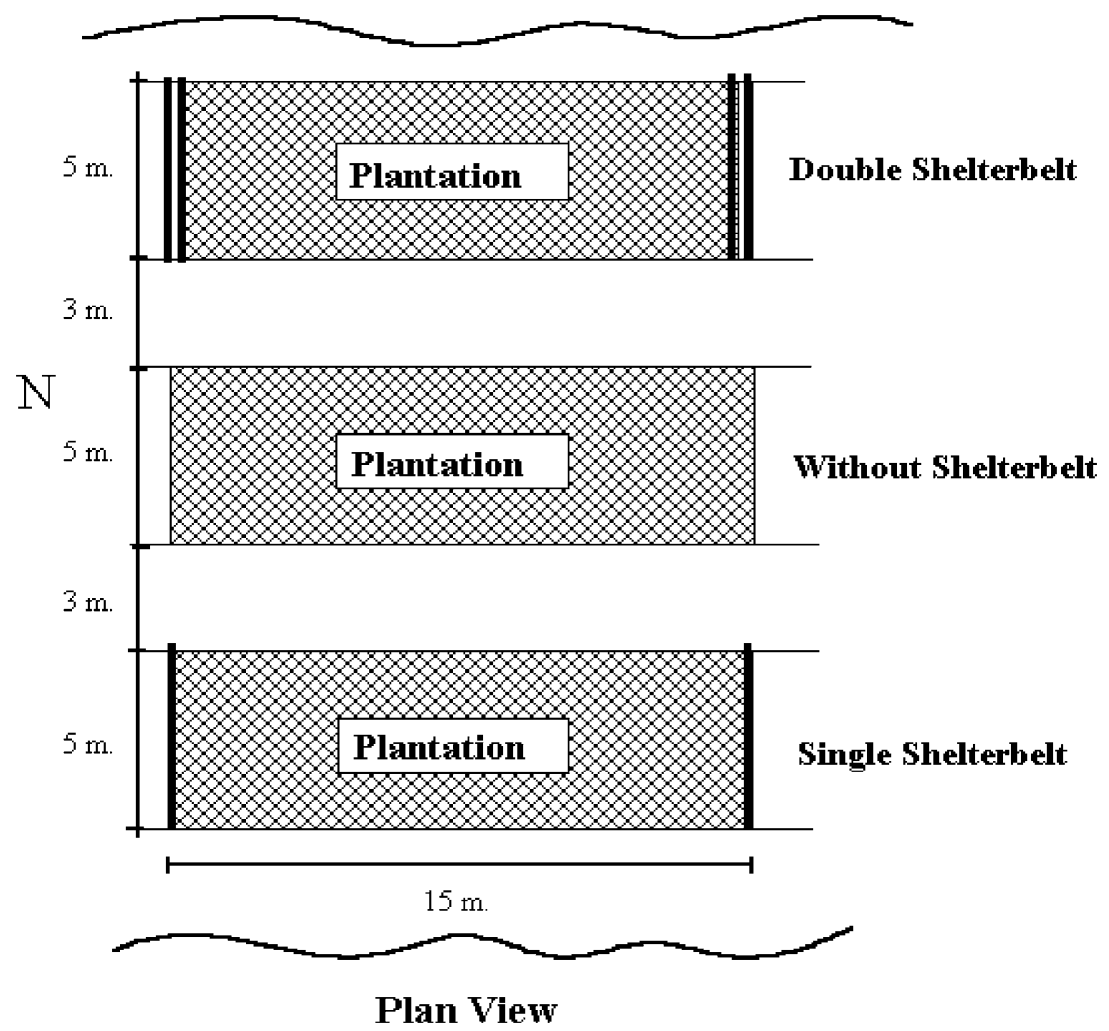

Fig. 2. Wind breaks disposition (plan view). 
plantations with an average height of $20 \mathrm{~cm}$. A more detailed description can be found in [32]. The herbaceous single- and double-row shelterbelts were sown at the northern and southern sides of the protected plots, at a rate of 100 seeds $^{-1}$, along E-W oriented rows, perpendicular to the strong prevailing northern and southern winds. The approximate average optical porosities of the single and double shelterbelts were $50 \%$ and $30 \%$, respectively. Figs. 2 and 3 outline this arrangement. Fig. 3 indicates also different distances from the shelterbelts at which wind measurements were carried out. The wooden fences were in a similar pattern.

A representative photograph of the windbreak was taken at an angle perpendicular to the shelterbelts. The photograph was scanned into a PC and its contrast was enhanced in order to obtain a black silhouette of the windbreak against a white background. A grid was superimposed and the porosity was estimated through counting the black and white cells. It is to be noted that the upper part of the herbaceous windbreaks was irregular with gaps between the highest ears and leaves. Fig. 4 shows their vertical porosity distribution. After the growth period, the average height $(H)$ of the single- and double-row shelterbelts was $70 \mathrm{~cm}$. The average widths of the single- and double-row shelterbelts were 25 and $40 \mathrm{~cm}$, respectively.
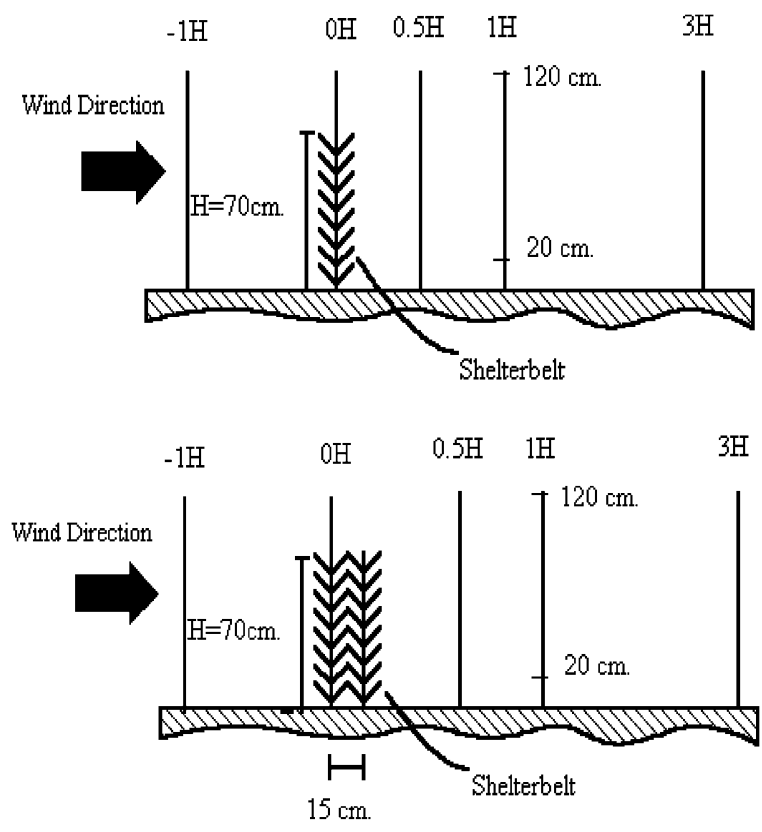

Double Shelterbelt

Fig. 3. Wind breaks disposition (lateral view). 


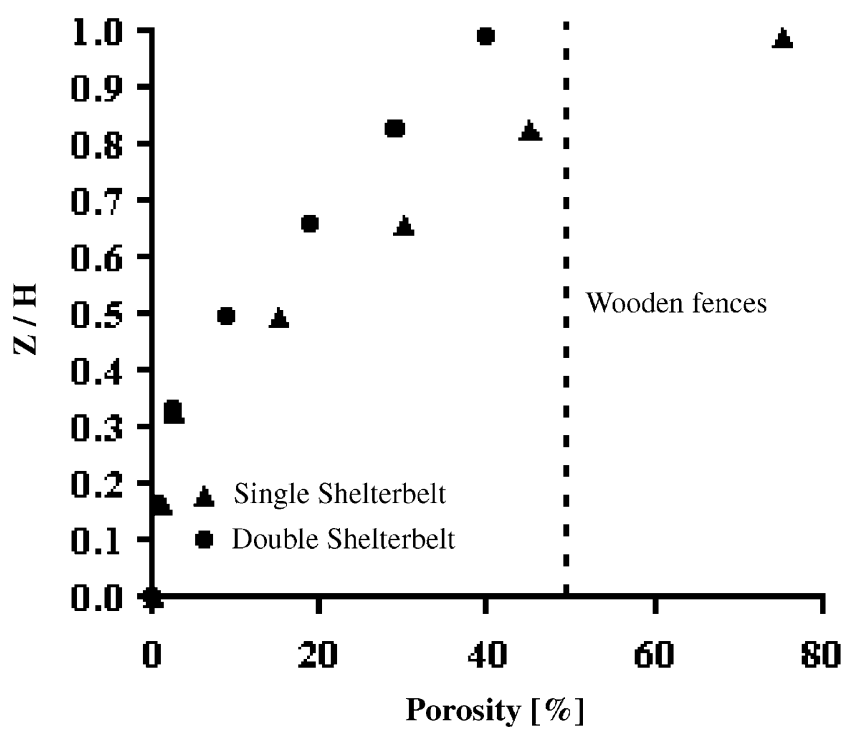

Fig. 4. Vertical porosity distribution of herbaceous shelterbelts and wooden fences.

\subsection{Wood fences}

One meter high and $7 \mathrm{~m}$ long fences were built, with horizontal wooden boards. The first fence with five horizontal $10 \mathrm{~cm}$ wide boards, separated by $10 \mathrm{~cm}$ horizontal gaps will be referred to as wide fence (WF); the second fence, with 10 horizontal $5 \mathrm{~cm}$ wide boards with $5 \mathrm{~cm}$ gaps will be called narrow fence (NF). Both types of fences had the same average porosity of 50\%. The fences were installed on August 17, 1999 contiguous to non-sheltered reference plots of equal area.

\subsection{Flow field measurements}

In order to study the wind sheltering characteristics during the growth process, when the plants are very sensitive to wind effects, the turbulence measurements were performed 7 weeks after sowing, when the average height of the wheat plantations was only $20 \mathrm{~cm}$. Their final height was $60 \mathrm{~cm}$.

The measurements were carried out in days of southern wind. It is expected that the changes in the flow introduced by the south-facing windbreaks will be similar to those produced by the north-facing windbreaks in days of northern winds.

A two-dimensional Cartesian co-ordinate system was located on the soil, at the middle of a fence, with the $x$-axis in the horizontal streamwise direction and the upward oriented vertical $z$-axis. The velocity components were $u$ (longitudinal, in $x$-direction) and $w$ (vertical), respectively. The flow analysis was two-dimensional, taking into account only the longitudinal and the vertical components. The reference 
length $H$ represented the windbreak height, for the Triticale or the fences, respectively.

The analysed flow measurements behind the shelterbelts were performed at $x / H=1$. The measurements were carried out using a two-channel Dantec constant temperature hot wire anemometer with X-wire probes (DANTEC 55R51). On-line spectra and autocorrelation analysis with preliminary high sampling rates, indicated frequency ranges well below $10 \mathrm{~Hz}$. To take into account small canopy elements vibrating at higher frequencies, generating small-scale turbulence, we selected a sampling frequency of $500 \mathrm{~Hz}$.

The transducer signals were conveniently filtered to remove the energy at higher frequencies and the high frequency noise. Considerations about aspects of the involved turbulent structures have been achieved by means of spectral and wavelet analysis in selected points within the mixing layer and bleed flow region.

\section{Experimental results}

\subsection{Flow analysis}

\subsubsection{Mean velocities, turbulence intensities and skewness}

Fig. 5 shows the mean velocity profiles, measured $1 H$ downstream of each barrier, and compared with measurements obtained in free wind conditions, indicated on the legend as "wind". Values were made non-dimensional being divided by $U_{\mathrm{h}}$, the mean velocity at the barrier height.

The wooden fences altered only slightly the shape of the downwind mean velocity profile. Differences with the incident flow produced by the wooden fences were observable in the longitudinal and vertical turbulence intensity distributions.
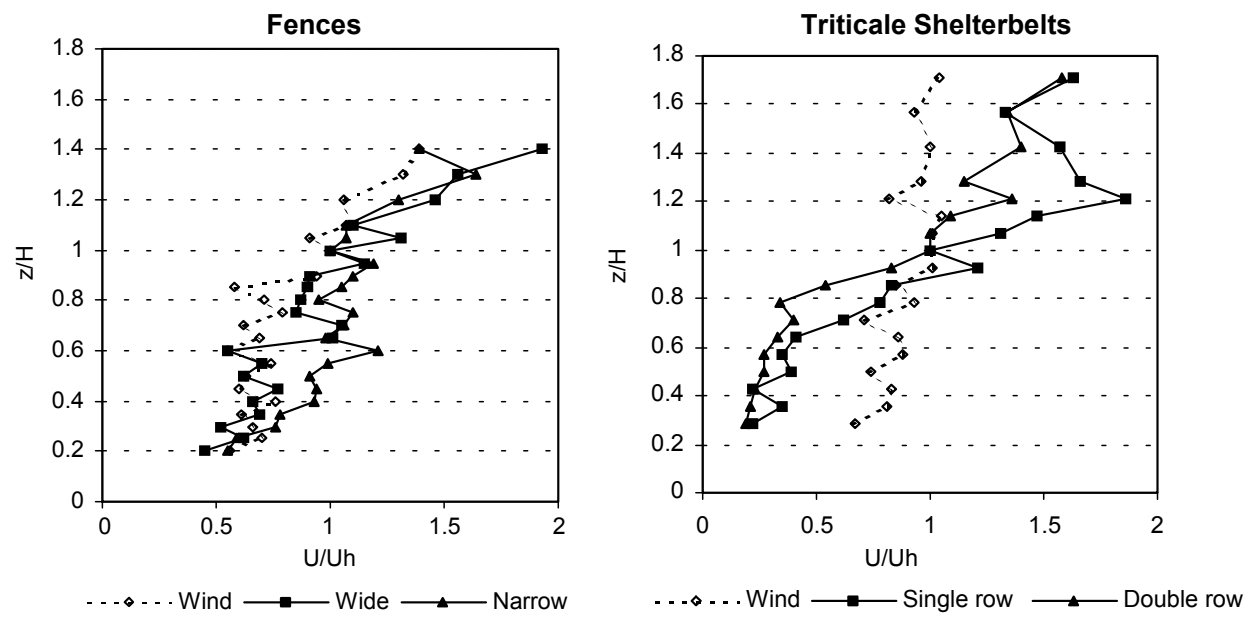

Fig. 5. Mean velocity distribution: $x / H=1$. 
We consider the turbulence intensity at a given height as

$$
T_{u}=\frac{\sigma_{u}}{U}, \quad T_{w}=\frac{\sigma_{w}}{U}
$$

with $\sigma_{u}$ and $\sigma_{w}$ the standard deviations for $u$ and $w$, and $U$ the mean velocity at the same height.

At fence top height both types of fences generated a moderate increase in the longitudinal turbulence intensity. Within the upper region $0.8<z / H<1.3$ the vertical turbulence intensity distributions exhibited larger values for WF than for NF as shown in Fig. 6. The largest differences were found for the vertical $w$-turbulence intensity at $z / H=1.1$, showing for WF a $70 \%$ turbulence intensity enhancement in comparison with NF. In the wake flow region of WF at $z / H=0.6$ a peak in the $w$ turbulence intensity distribution was observed. In contrast, at the same height, NF showed a turbulence intensity reduction in comparison with the free wind levels.

The flow behind the herbaceous shelterbelts showed a different behaviour (Fig. 5). The mean velocity distribution revealed the lower bleed flow zone, with reduced mean velocity, and the upper high velocity shear layer region. Behind both types of herbaceous shelterbelts, an inflection point mean velocity distribution was found, as characteristic for canopy flows [33]. The flow behind the single- and double-row
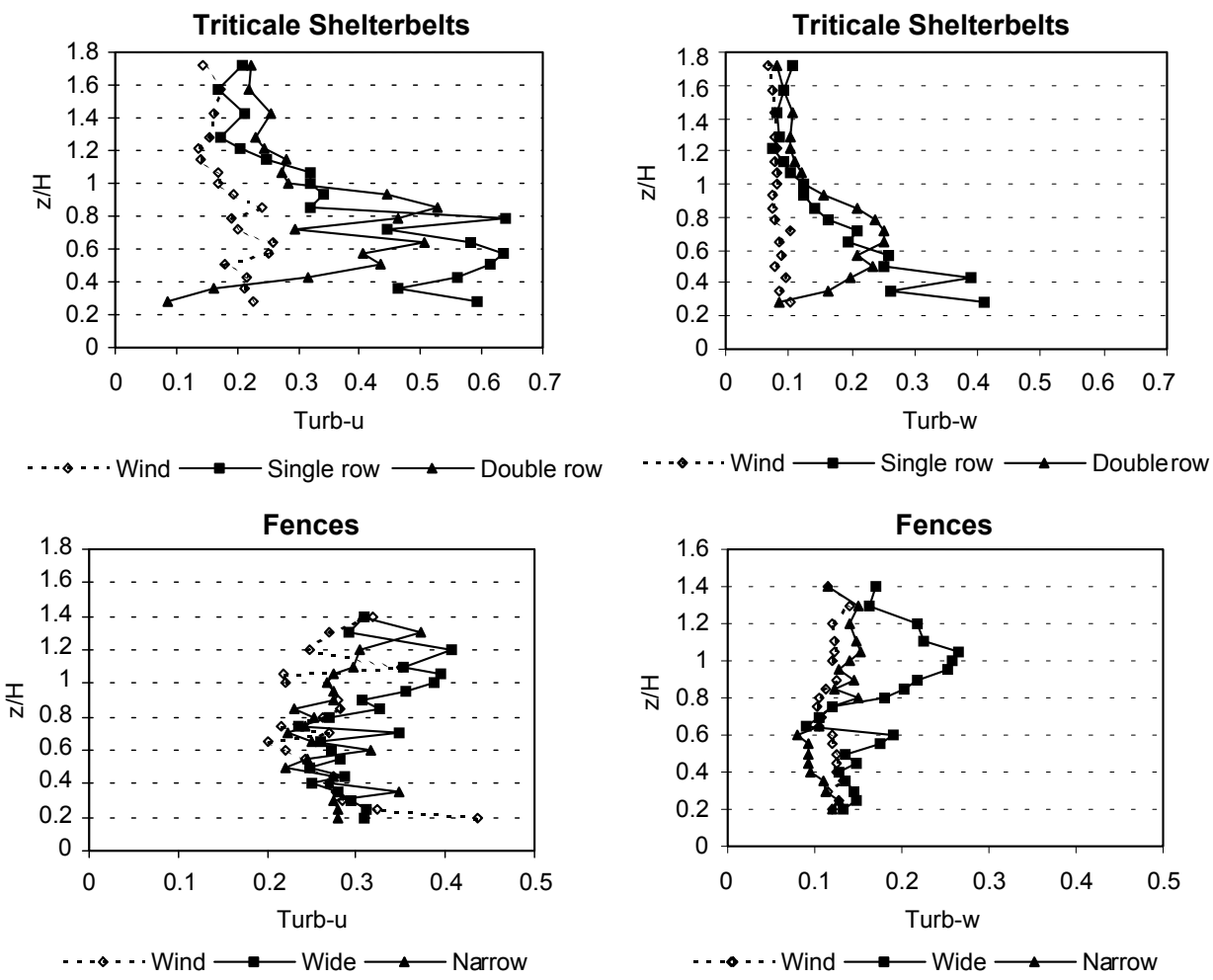

Fig. 6. Turbulence intensity distribution: $x / H=1$. 
shelterbelts showed a turbulence increase in comparison with the free wind conditions. The single-row shelterbelts exhibited larger turbulence intensities than the double-row shelterbelts below $z / H=0.6$, where the latter revealed smaller values than for higher levels.

A qualitative difference was observed below $z / H=0.6$ : while the single-row shelterbelt increased the turbulence levels at all heights for both velocity components, the turbulence downwind of the double row reached a maximum and decreased below. At $z / H=0.2$ it was lower than the turbulence of the free wind. The double-row shelterbelt reduced the velocity fluctuations on a higher degree than the mean velocity, in contrast to the opposite behaviour of the single row.

The windbreaks introduced important changes in the values of skewness, a parameter that quantifies the positive-negative asymmetry of the velocity fluctuations. The herbaceous shelterbelts introduced large positive values of $u$-skewness in the protected zone, compared with the free wind distribution. This behaviour is qualitatively similar to a mixing layer flow, as stated by Raupach et al. [33]. Negative skewness values were found for the vertical component $w$ in the shear layer and in the lower bleed flow region of the double shelterbelt. This behaviour was not found at lower heights behind the single shelterbelt, where the $w$-skewness was similar to that of the uniform porosity fences (Fig. 7).

For the wooden fences, the $u$-skewness distribution showed a complex behaviour. Within a large region behind both types of wooden fences, the flow exhibited positive $u$-skewness values, ranging from 0.4 to 1.7 . At two points $(z / H=0.6$ and 0.35$)$ behind NF, intense $u$-skewness peaks were detected. At the same heights, the $w$-skewness distribution showed much weaker peaks. The large negative $w$-skewness detected within the fence-top shear layer suggests a downward momentum penetration from the more energetic upper flow.

\subsubsection{Spectral and wavelet transform analysis}

Results shown in Figs. 8 and 9 are presented for the flow at $z / H=1$, at a downwind distance $x / H=1$. The spectra have been processed with a Hanning window, and averaged from eight blocks in order to reduce uncertainty. The different scales for representing the horizontal and vertical velocity spectra should be noticed.

At fence top height the spectral analysis of the longitudinal velocity component showed the highest spectral power density (SPD) levels at frequencies below $2 \mathrm{~Hz}$. The kinetic energy contents were higher for the flow downstream of WF than for NF, and higher for the single row of Triticale than for the double row. This behaviour was consistent with the corresponding turbulence intensity distributions. The appearance of the four longitudinal velocity spectra was qualitatively similar, with decreasing SPD at higher frequencies. Nevertheless, the vertical component $w$ spectra behind the wooden fences and the herbaceous shelterbelts showed different behaviour.

The vertical velocity spectra for the shelterbelts exhibited lower spectral amplitudes than the $u$-spectra and a slower attenuation rate towards higher frequencies. Behind the herbaceous shelterbelts the largest $w$-spectral amplitude 

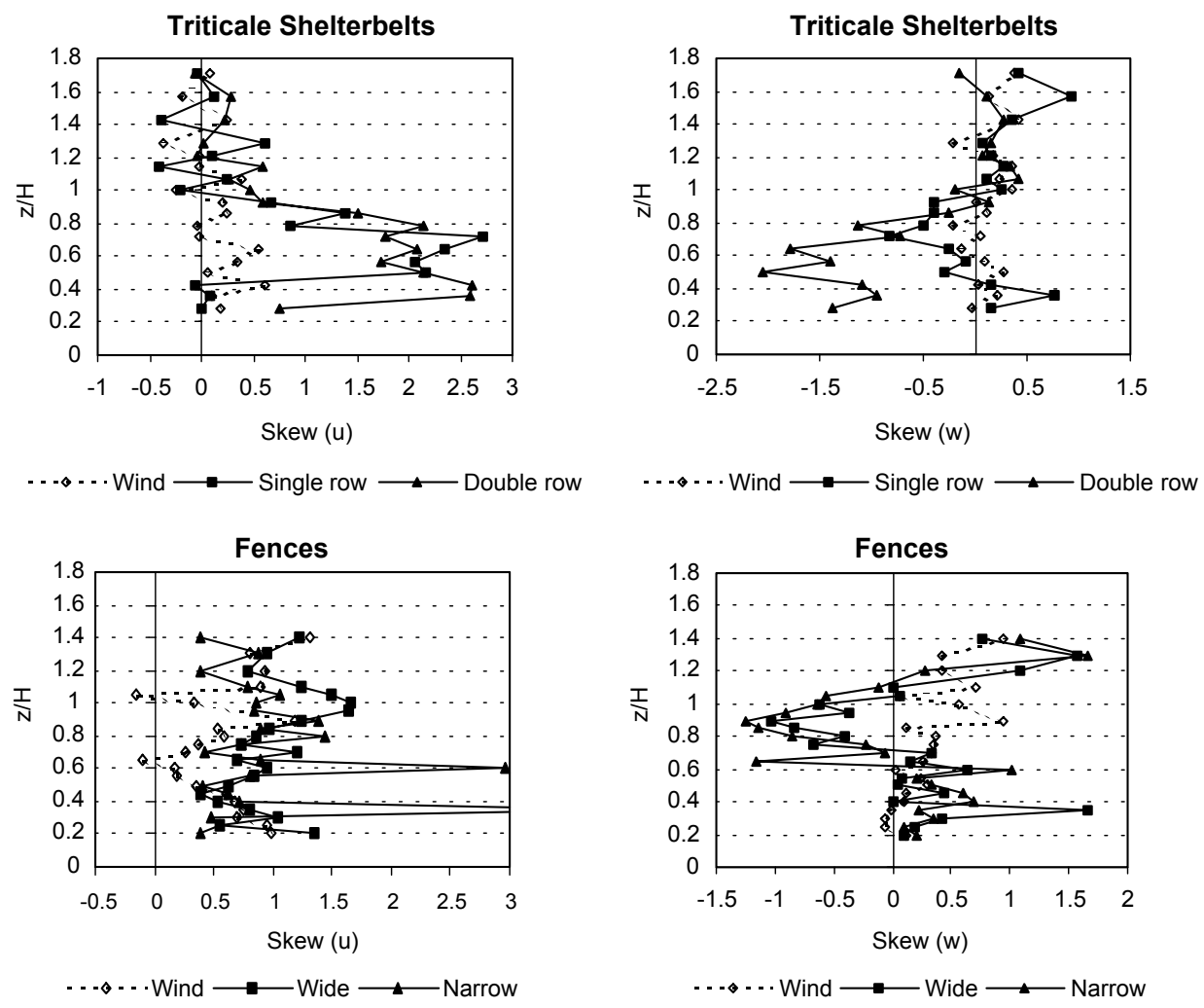

Fig. 7. Skewness distribution: $x / H=1$.

decreases were measured. The $w$-spectral amplitude attenuation of the fences was not so marked. Behind the WF the largest amplitudes were measured, with several peaks, revealing a distribution of energy between 0 and $10 \mathrm{~Hz}$. Behind the NF a smaller amplitude $w$-spectra was found, with lower peaks and a moderate maximum at $4 \mathrm{~Hz}$.

In what follows we have used the continuous wavelet transform [34,35]

$$
W(s, \tau)=\frac{1}{s^{1 / 2}} \int_{-\infty}^{+\infty} f(t) \psi\left(\frac{t-\tau}{s}\right) \mathrm{d} t
$$

with $f(t)$ the time-dependent signal to be analysed, $s$ the scale, and $\tau$ the time localisation of the wavelet $\psi$. Our aim was to compare time scales and intensities in the wavelet map, associated with aspects of large-scale organised structures, which are embedded within the turbulent flow behind the shelterbelts and are able to transport and inject strong gusts within the protected region.

Within the shear layer region it seems reasonable to expect intermittent generation of some type of roll vortices, with high velocity regions in the periphery of their cores. We followed qualitatively some wavelet interpretation criteria used by Mahrt [36], estimating the time extent of a particular detected structure directly from its 

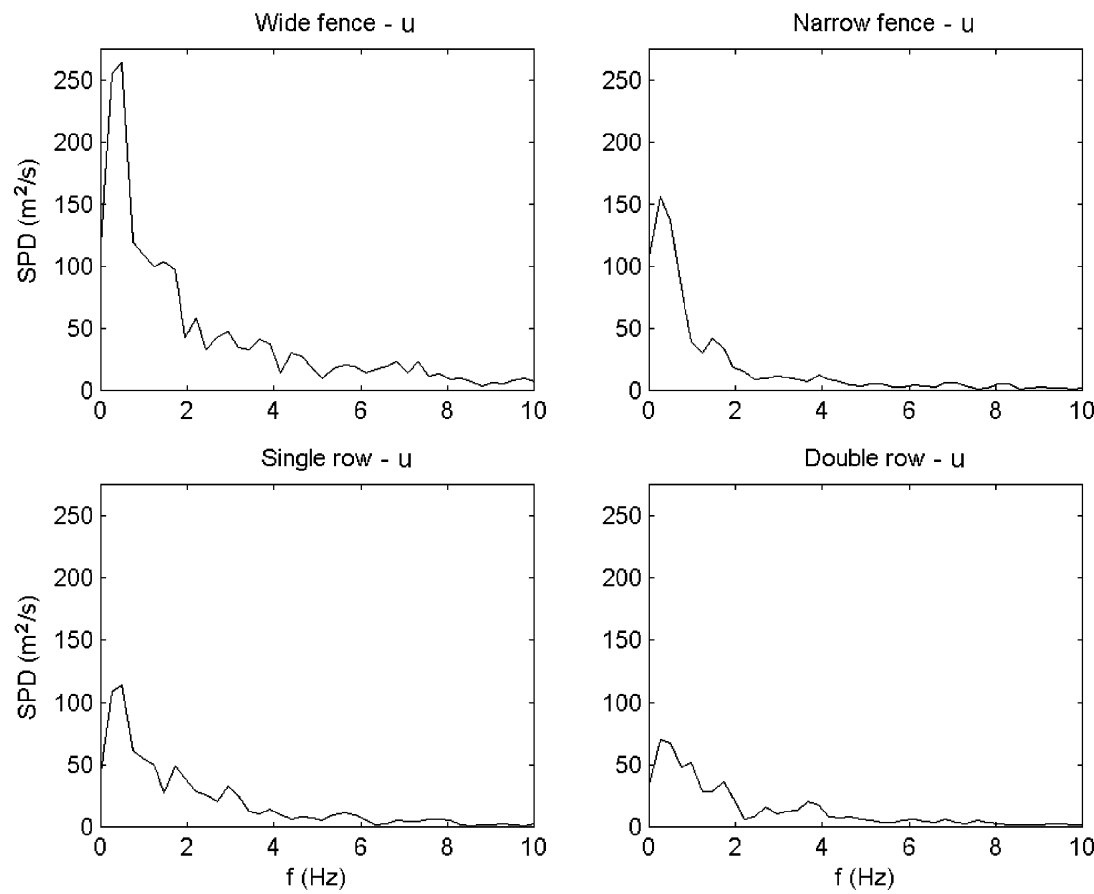

Fig. 8. Spectral power density for the longitudinal velocity component $u: x / H=1, z / H=1$.

wavelet graph scale. We explored the velocity-time records in order to detect features related to the second derivative of a Gaussian $g_{2}$ (usually called the 'Mexican hat' wavelet).

Fig. 10 shows wavelet analysis of data taken at the windbreak heights at a distance of $x / H=1$. Confirming the spectral results, the graph shows that the wide fence shear layer contained more energetic structures than the narrow fence. The time scale of these structures, of poor resolution in the SPD graph, is seen here to be 1-3 s. Analysis of the vertical velocity component (not shown) also evidenced the frequent penetration of descending gusts downstream of the wide fence. This fact was also supported by the turbulence and skewness behaviour.

Even for moderate winds the upper part of the herbaceous barrier experienced sway motions of considerable amplitude. Field observation indicated that the single-row shelterbelt undergoes more intense swaying than the double one. The time scales around $1 \mathrm{~s}$, which appeared as the most energetic in the wavelet map, matched the natural frequency of the shelterbelts sway motion, of the order of $1 \mathrm{~Hz}$. The more energetic maxima in the $u$-evolution of the single-row barrier might be a trace of aspects of this aeroelastic behaviour. At lower levels, the ability to extract more energy from the oncoming flow by the wider double-row shelterbelt was reflected in a reduced frequency of the large structures and in their smaller energies. 

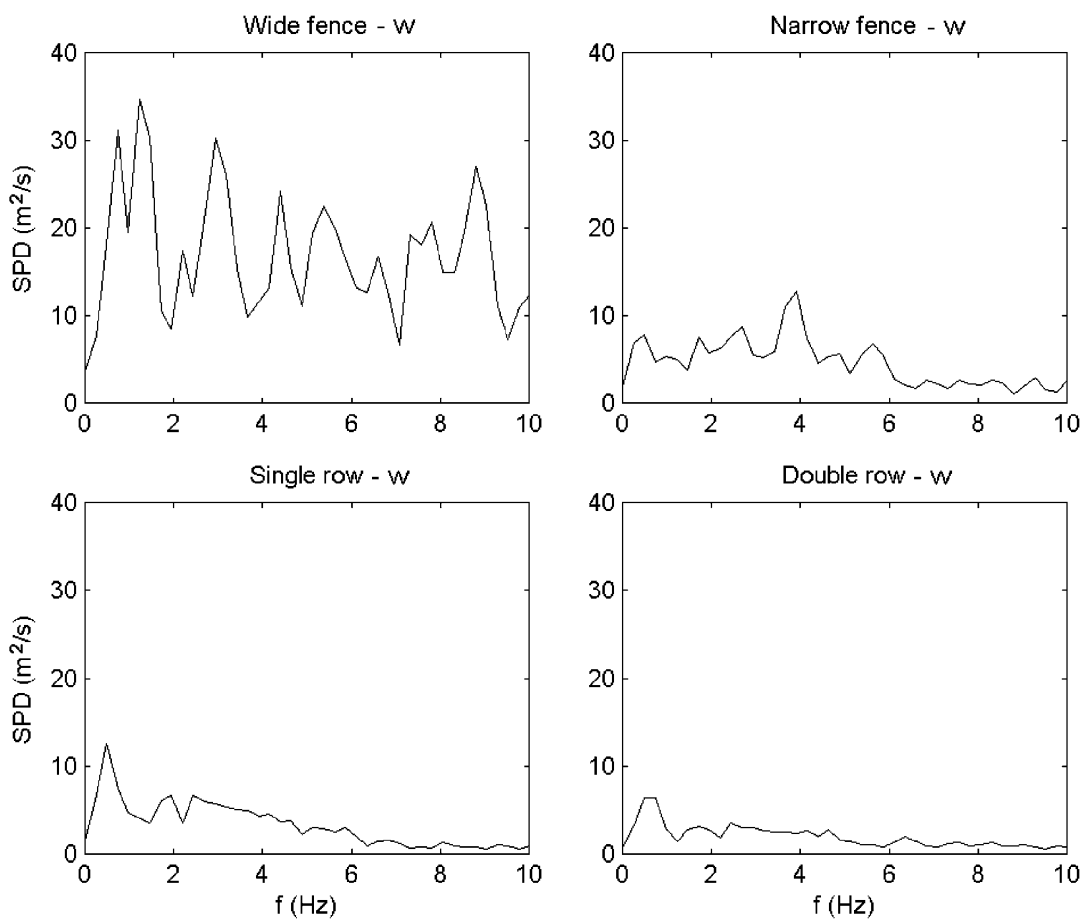

Fig. 9. Spectral power density for the vertical velocity component $w: x / H=1, z / H=1$.

It is known [37] that in wavelet transform analysis, incoherent noise due to the signal's power spectrum can mask some traces of coherent structures. Hence we have used the wavelet transform as a complementary tool, taking from the wavelet graphs the information that confirms, complements and expands the results of classical turbulence statistics and spectral analysis.

\subsection{Comparison of sheltered and unsheltered wheat response}

\subsubsection{Grain yield}

Comparing results with and without natural shelterbelts (Fig. 11), the grain yield was higher in all cases for the protected subplots. Important yield increases have been found behind the herbaceous shelterbelts. Yield improvements of $54 \%$ and $32 \%$ have been measured for the plants protected by the southern- and northernfacing double-row shelterbelts. Behind the southern- and northern-facing single-row shelterbelts, increases of $31 \%$ and $37 \%$ have also been found. On the other hand, the yield behaviour of plants protected by the wooden fences was ambiguous. The plants protected by the north-facing wide fences showed a yield increase of $30 \%$ while the plants sheltered by the narrow fence showed an increase of only 5\%. Behind the south-facing wide fence a yield increase of $18 \%$ was found. In contrast, the subplots behind the narrow fence showed a surprising yield decrease of $22 \%$. 

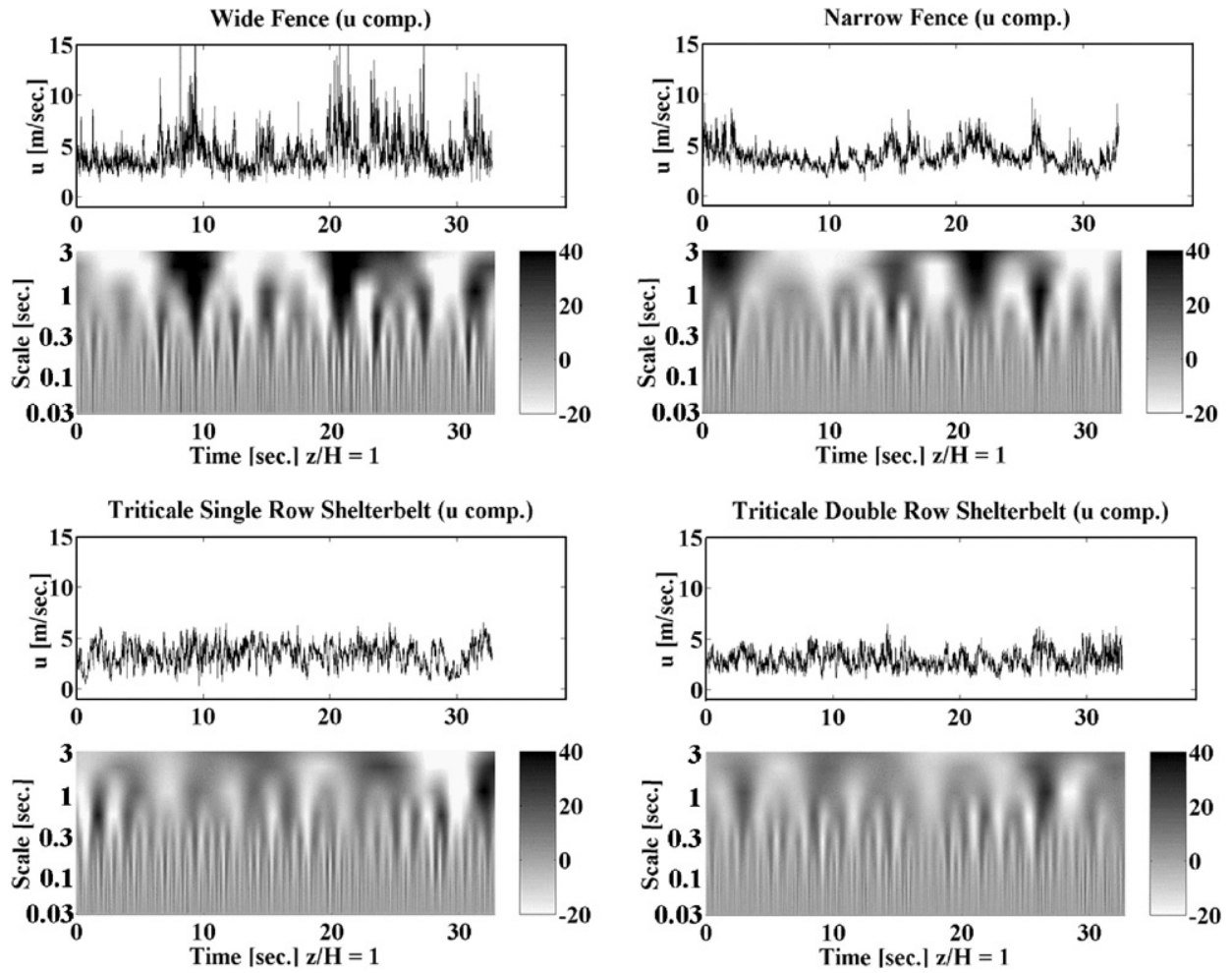

Fig. 10. Wavelet maps of the longitudinal velocity component $(u)$ for both fences and both herbaceous shelterbelts at $z / H=1, x / H=1$.

\subsubsection{Harvest index}

HI increases were found behind the herbaceous shelterbelts. Following the southfacing double-row shelterbelts, HI increases of $15 \%$ were found, while behind the north-facing double-row shelterbelts HI increases of only $3 \%$ were obtained. The subplots protected by south- and north-facing single-row shelterbelts showed increases of $7 \%$ and $12 \%$, respectively. The $\mathrm{HI}$ of plants sheltered by wooden fences exhibited a complex behaviour: behind the north-facing wide fence a HI decrease of $7 \%$ was found. The same HI as for unsheltered plants was obtained behind the north-facing narrow fences. The crop behind both types of south-facing fences showed substantial HI reductions. After the wide fence, a decrease of $24 \%$ was found. Behind the narrow fence the decrease was $15 \%$.

\section{Discussion}

The fluid dynamic statistics downstream of the herbaceous shelterbelts exhibit features qualitatively similar to those for canopy flows described by 

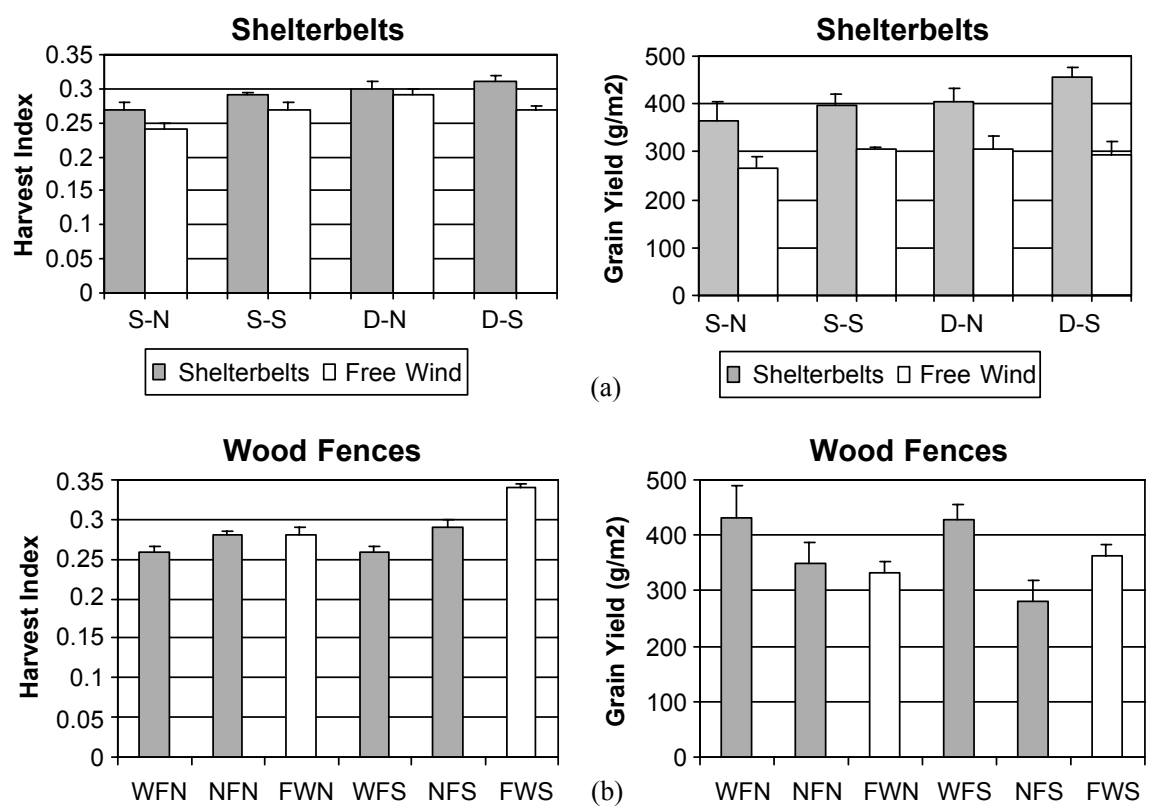

Fig. 11. (a) S-N: Single shelterbelt, protection from northern winds, S-S: single shelterbelt, protection from southern winds, D-N: double shelterbelt, protection from northern winds, D-S: double shelterbelt, protection from southern winds. (b) WF, NF and FW stand for wide fence, narrow fence and free wind, respectively. The last $\mathrm{N}-\mathrm{S}$ means protected from northern-southern winds, respectively.

Raupach et al. [33], with two distinct zones: a low mean velocity bleed flow region, with high turbulence levels, and an upper shear layer region. The different porosities of the two types of herbaceous shelterbelts caused different turbulence distributions, with a marked turbulence attenuation behind the double row, which was not detected for the flow behind the single-row shelterbelt. The single- and double-row shelterbelts enhanced the grain yield and the HI of the protected wheat plants.

The largest yield increases were measured behind south-facing double-row shelterbelts. Explanations for this may take into account the milder nature of northern winds. One of the most characteristic and strongest winds of the Pampa region is the Pampero. It blows from $\mathrm{S}$ and $\mathrm{SW}$, producing colder temperatures and lower humidity than northern winds. This wind, shielded by the south-facing fences, could be particularly stressing to the plants.

Both types of wooden fence had the same overall porosity, but generated wakes with different turbulence. The influence of the wooden fences in changing the mean velocity distribution was weaker than their influence on the turbulence intensity and skewness distributions. The turbulence at fence height was more energetic than for the herbaceous shelterbelts, as illustrated by the spectral and wavelet analysis. It seems reasonable to infer that the strong vertical fluctuations associated with 
large-scale structures detected in the wavelet analysis within the WF top shear layer, are related to the downward transport of momentum. Therefore, the differences in the response of plants protected by the narrow and wide gap fences might be attributed to the different structure of turbulence.

It seems reasonable to hypothesise that different fence porosity distributions could also behave as perturbing factors, able to influence the fence top shear layer generation process and thus the corresponding shear layer turbulent structures. It is known that adequate perturbations induce modifications of the spreading rate of the upper mixing layer, its turbulence intensity distribution and the downwind evolution of the Reynolds stresses, influencing the extension and characteristics of the wake region and the ability of a fence in preventing injury to plants [38]. At constant porosity, the more intense bleed flow passing through the fewer but wider gaps of the WF was balanced by enlarged low velocity zones behind the wider planks. This effect behind the WF may have contributed to the detected turbulence intensification within the fence top shear layer.

The influence of the wooden fences on plant growth was not so clear. The largest HI decrease was measured behind the south-facing wide fence. Nevertheless, the grain yield was higher than for the plants exposed to the wind. In contrast, the wheat protected by the narrow fence showed reductions in both parameters. This confirms the findings of Wadsworth [18] who suggested the existence of an optimum wind speed for plant growth, depending on plant species and soil water potential. Analysing the behaviour of Brassica napus he reported growth rate increases of about $10 \%$ at a wind speed of $0.7 \mathrm{~ms}^{-1}$ while increasing the speed to $4 \mathrm{~ms}^{-1}$ caused a noticeable growth rate reduction. The present results additionally suggest the influence of turbulence structure in this process.

It is possible then to infer that different combinations of larger scales and increased turbulence intensity had an effect on the reported positive and negative growth effects.

It is interesting to point out that herbaceous annual shelterbelts are profitable and can be easily managed by the farmer. Herbaceous shelterbelts exhibit several advantages over artificial and wooden shelterbelts because they are cheaper, uncomplicated, and allow a rapid installation. Annual herbaceous shelterbelts like the Triticale can be harvested and tolerate more flexibility in the farming business.

As the plant response data presented in this paper were only one-season results, the agronomical findings must be interpreted with care. Further experimental work involving a number of years is essential to consider effects due to the occasional occurrence of extremely intense winds, the yearly variability of meteorological conditions and the influence of location, soil and management practices.

\section{Acknowledgements}

Part of this work was sponsored by the Agencia de Promocion Cientifica y Tecnologica, Argentina. 


\section{References}

[1] J.K. Raine, D.C. Stevenson, Wind protection by model fences in a simulated atmospheric boundary layer, J. Indust. Aerodyn. 2 (1977) 159-180.

[2] E.F. Bradley, P.J. Mulhearn, Development of velocity and shear stress distributions in the wake of a porous shelterbelt, J. Wind Eng. Indust. Aerodyn. 15 (1983) 145-156.

[3] M.D. Perera, Shelter behind two-dimensional solid and porous fences, J. Wind Eng. Indust. Aerodyn. 8 (1981) 93-104.

[4] A.J. Papesch, Wind tunnel tests to optimize barrier spacing and porosity to reduce wind damage in horticultural shelter systems, J. Wind Eng. Indust. Aerodyn. 41-44 (1992) 2631-2642.

[5] M. Jensen, Shelter Effect: Investigations Into the Aerodynamics of Shelter and Its Effects on Climate and Crops, The Danish Technical Press, Copenhagen, 1954, 263pp.

[6] J. Borrelli, J.M. Gregory, W. Abtew, Wind barriers: a re-evaluation of height spacing and porosity, Amer. Soc. Agric. Eng. Paper 87-2031, 1987.

[7] R.M. Argent, The influence of a plant canopy on shelter effect, J. Wind Eng. Indust. Aerodyn. 41/44 (1992) 2643-2653.

[8] J. Kort, Benefits of windbreaks to field and foprage crops, Agric. Ecosyst. Environ. 22/23 (1988) $165-190$.

[9] J.R. Brandtle, B.B. Johnson, T. Akeson, Field windbreaks: Are they economical?, J. Prod. Agric. 5 (1992) 393-398.

[10] P.J. Mulhearn, E.F. Bradley, Secondary flows in the lee of porous shelterbelts, Bound. Layer Meteorol. 12 (1977) 75-92.

[11] E. Plate, The aerodynamics of shelter belts, Agric. Meteorol. 8 (1971) 203-222.

[12] D.W. Fryrear, J.D. Downes, Estimating seedling survival from wind erosion parameters, Trans. ASAE 18 (1975) 888-891.

[13] F.W. Telewski, Wind-induced physiological and developmental responses in trees, in: M.P. Couttsand, J. Grace (Eds.), Wind and Trees, Cambridge University Press, Cambridge, 1995, pp. 237-263.

[14] J.J. Finnigan, M.R. Raupach, Transfer processes in plant canopies in relation to stomatal characteristics, in: E. Zeiger, G.D. Farquhar, I.R. Cowan (Eds.), Stomatal Functions, Stanford University Press, 1987, pp. 385-429.

[15] H. Bergström, U. Högström, Turbulent exchange above a pine forest. Part II. Organized structures, Bound. Layer Meteorol. 49 (1989) 231-263.

[16] M.R. Raupach, J.J. Finnigan, Y. Brunet, Coherent eddies in vegetation canopies, Proceedings of the Fourth Australasian Conference on Heat and Mass Transfer, Christchurch, New Zealand, 9-12 May 1989, pp. 75-90.

[17] W. Gao, R.H. Shaw, K.T. Paw, Observation of organized structure in turbulent flow within and above a forest canopy, Bound. Layer Meteorol. 47 (1989) 349-377.

[18] R.M. Wadsworth, An optimum wind speed for plant growth, Ann. Bot. 23 (1959) 195-199.

[19] M.J. Jaffe, Wind and other mechanical effects in the development and behaviour of plants with special emphasis on the role of hormones, in: R.P. Pharis, D.M. Reid (Eds.), Encyclopedia of Plant Physiology 11, Springer, Berlin, 1985, pp. 444-483.

[20] M. Dixon, J. Grace, Effects of wind on the transpiration of young trees, Ann. Bot. 53 (1984) 811-819.

[21] J. Grace, M. Dixon, Convective heat transfer from leaves, in: J. Grace (Ed.), Effects of Shelter on the Physiology of Plants and Animals, Swets \& Zeitlinger, Lisse, 1985, 176pp.

[22] F.W. Telewski, M.J. Jaffe, Thigmomorphogenesis: field and laboratory studies of Abies fraseri in response to wind or mechanical perturbation, Physiol. Plant 66 (1986) 211-218.

[23] A. Stokes, A.H. Fitter, M.P. Coutts, Responses of young trees to wind, in: M.P. Coutts, J. Grace (Eds.), Wind and Trees, Cambridge University Press, Cambridge, 1995, pp. 264-275.

[24] A.M. Goodman, A.R. Ennos, The responses of field-grown sunflower and maize to mechanical support, Ann. Bot. 79 (6) (1997) 703-711.

[25] A.M. Goodman, A.R. Ennos, Responses of the root systems of sunflower and maize to unidirectional stem flexure, Ann. Bot. 82 (3) (1998) 347-357. 
[26] C.J. Baker, P.M. Berry, J.H. Spink, R. Sylvester-Bradley, J.M. Griffin, R.K. Scott, R.W. Clare, A method for the assessment of the risk of wheat lodging, J. Theor. Biol. 194 (1998) 587-603.

[27] P.M. Berry, J.M. Griffin, R. Sylvester-Bradley, R.K. Scott, J.H. Spink, C.J. Baker, R.W. Clare, Controlling plant form through husbandry to minimise lodging in wheat, Field Crops Res. 67 (2000) $59-81$.

[28] N.J. Rosenberg, B.L. Blad, S.B. Verma, Microclimate, in: N.J. Rosenberg, B.L. Blad, S.B. Verma (Eds.), The Biological Environment, 2nd Edition, Wiley, New York, 1983, 495pp.

[29] J.D. Wilson, On the choice of a windbreak porosity profile, Bound. Layer Meteorol. 38 (1987) 37-49.

[30] F. Grunert, D. Benndorf, K. Klingbeil, Neuere Ergebnisse zum Aufbau von Schutzpflanzungen, Beitr. Forstwirtschaft 18 (1984) 108-115.

[31] K.G. McNaughton, Effects of windbreaks on turbulent transport and microclimate, Agric. Ecosyst. Environ. 22/23 (1988) 17-39.

[32] U. Boldes, J. Colman, J. Marañón Di Leo, Field study of the flow behind single and double row herbaceous windbreaks, J. Wind Eng. Indust. Aerodyn. 89 (2001) 665-687.

[33] M.R. Raupach, J.J. Finnigan, Y. Brunet, Coherent eddies and turbulence in vegetation canopies: the mixing layer analogy, Bound. Layer Meteorol. 78 (1996) 351-382.

[34] M. Farge, Wavelet transforms and their applications to turbulence, Ann. Rev. Fluid Mech. 24 (1992) 395-457.

[35] M. Farge, Transformee en ondelettes continue et application a la turbulence, J. Annu. Soc. Math. France (May 1990) 17-62.

[36] L. Mahrt, Eddy asymmetry in the sheared heated boundary layer, J. Atmos. Sci. 48 (1991) 472-492.

[37] J. Dunyak, X. Gilliam, R. Peterson, D. Smith, Coherent gust detection by wavelet transform, J. Wind Eng. Indust. Aerodyn. 77\&78 (1998) 467-478.

[38] C.M. Ho, P. Huerre, Perturbed free shear layers, Ann. Rev. Fluid Mech. 16 (1984) 365-424. 